\title{
EFEKTIFITAS PENYULUHAN KESEHATAN TERHADAP PENCEGAHAN STUNTING DI KLINIK MARIANA
}

\author{
Patimah Sari Siregar $^{1}$, Kristina L Silalahi ${ }^{2}$, Eva Latifah Nurhayati ${ }^{3}$ \\ ${ }^{1,2,3}$ Fakultas Keperawatan dan Kebidanan, Universitas Prima Indonesia \\ Email: patimahsarisiregar@unprimdn.ac.id
}

\begin{abstract}
Stunting is a chronic nutritional problem in toddlers characterized by a shorter height compared to other children of their age. Children who suffer from Stunting will be more susceptible to disease and as adults are at risk for degenerative diseases. Health counseling is held to increase the knowledge, awareness, willingness, and ability of mothers to continue to provide good nutrition during pregnancy. Knowledge of feeding is from pregnancy to prevent Stunting. Research that focuses on intention, motivation, and knowledge is not sufficient to help mothers overcome obstacles during pregnancy. Besides getting counseling, mothers overcome obstacles during pregnancy. In addition to getting maternal counseling, it requires support, education, and information that is consistent, realistic, and evidence-based to successfully improve nutrition during pregnancy. The goal is to find out the effectiveness of health education on Stunting prevention at the Mariana Clinic. The research will be conducted using a QuasiExperiment design (quasi-experimental), with the target that pregnant women are given counseling. The methods of data collection are using questionnaires, interviews, and observations. The data analysis method used the dependent t-test, namely the Wilcoxon test. In the paired group, the same subjects were examined before and after the intervention (before and after design) of the questionnaire as a research instrument. The test used is the Wilcoxon test. The results study based on the Wilcoxon test, it was found that the p-value $(<0.05)$ statistically showed that there was the effectiveness of health education on the prevention of Stunting in pregnant women at the Mariana clinic ( $p$-value $=0.002$ ).
\end{abstract}

Keywords: Effectiveness, health education, prevention of Stunting

\section{PENDAHULUAN}

Stunting merupakan ancaman utama terhadap kualitas manusia, juga ancaman terhadap kemampuan daya saing bangsa (Kementerian Kesehatan RI, 2018). Stunting akan mengakibatkan tingkat kecerdasan tidak maksimal, menjadikan anak menjadi lebih rentan terhadap penyakit dan di masa depan dapat beresiko pada menurunya tingkat produktivitas. Pada akhirnya secara luas Stunting akan dapat menghambat pertumbuhan ekonomi, meningkatkan kemiskinan dan memperlebar ketimpangan (TNP2K, 2017).

Masalah Stunting merupakan salah satu permasalahan yang dihadapi di dunia, khususnya di negara-negara miskin dan berkembang. Stunting menjadi permasalahan karena berhubungan dengan meningkatnya resiko terjadinya kesakitan dan kematian, perkembangan otak sub optimal sehingga perkembangan motorik terhambat dan terlambatnya pertumbuhan mental (UNICEF, 2012). 
Masalah Stunting dipengaruhi oleh rendahnya akses terhadap makanan dari segi jumlah dan kualitas gizi, serta seringkali tidak beragam. Selanjutnya dipengaruhi juga oleh pola asuh yang kurang baik terutama pada praktek pemberian makan bagi bayi dan balita.

Selain itu, Stunting juga dipengaruhi dengan rendahnya akses terhadap pelayanan kesehaan, termasuk didalamnya adalah akses sanitasi dan air bersih. Pola asuh dan status gizi sangat dipengaruhi oleh pemahaman oraang tua (seorang ibu) maka, dalam mengatur kesehatan dan gizi dikeluarganya edukasi diperlukan agar dapat mengubah perilaku yang bisa mengarahkan pada peningkatan kesehatan gizi ibu atau ibu dan anaknya (Kementerian Kesehatan RI, 2018). Status gizi ibu hamil sangat mempengaruhi keadaan kesehatan dan perkembangan janin (Ni`mah Khoirun \& Nadhiroh, 2015). Gangguan pertumbuhan dalam kandungan dapat menyebabkan berat lahir rendah (World Health Organization (WHO), 2014b).

Status sosial ekonomi keluarga seperti pendapatan keluarga, pendidikan orang tua, pengetahuan ibu tentang gizi; dan jumlah anggota keluarga secara tidak langsung dapat berhubungan dengan kejadian Stunting (Ni`mah Khoirun \& Nadhiroh, 2015). Stunting adalah masalah kurang gizi kronis yang disebabkan oleh kurangnya asupan gizi dalam waktu yang cukup lama, sehingga mengakibatkan gangguan pertumbuhan pada anak yakni tinggi badan anak lebih rendah atau pendek (kerdil) dari standar usianya (Kemenkes RI, 2018).

Keluarga dengan pendapatan yang tinggi akan lebih mudah memperoleh akses pendidikan dan kesehatan sehingga status gizi anak dapat lebih baik (Bishwakarma, 2011). Penelitian yang dilalukan di Cina menunjukkan bahwa faktor ibu merupakan faktor resiko untuk Stunting antara lain ibu dengan anemia dan kurang gizi saat hamil masing-masing memiliki resiko 2 kali lebih tinggi dibanding dengan ibu yang tidak mengalami anemia atau kekurangan gizi saat hamil, serta pendidikan ibu yang rendah sekali lebih tinggi dibanding dengan ibu yang tidak mengalami anemia atau kekurangan gizi saat hamil, serta pendidikan bu rendah memiliki resiko 2 kali lebih tinggi dibandingkan ibu dengan pendidikan tinggi. Pada tahun 2017 22,2\% atau sekitar 15,8 juta balita di dunia mengalami Stunting, lebih dari setengah berasal dari Asia (55\%) sedangkan sepertiganya (39\%) di Afrika. Dari 83,6 juta balita Stunting di Asia, proporsi terbanyak di Asia selatan (58,7\%) (UNICEF, 2018). Data prevalensi balita Stunting WHO, Indonesia termasuk negara ketiga dengan prevalensi tertinggi di Asia Tenggara/Sout-Eaast 
Asia Tenggara (SEAR) adalah 36,4\% (WHO, 2014). Laporan Global Network Againts Food Crises (FAO, 2019) menunjukkan bahwa pada penutupan tahun 2019, 135 juta orang di 55 negara dan wilayah mengalami kerawanan pangan akut (IPC/CH Fase 3 atau lebih tinggi). Hasil Riset Kesehatan Dasar (Kementerian Kesehatan RI, 2018a) menunjukkan 30,8\% atau sekitar 7 juta balita menderita stunting.

Dalam menyikapi tingginya prevalensi Stunting ini, perlu dilakukan pencegahan. Sebanyak 55 negara krisis pangan yang tercakup dalam laporan tersebut, 75 juta anak mengalami Stunting dan 17 juta menderita wasting pada tahun 2019. Pencegahan Stunting dapat dilakukan melalui pendekatan gizi dan non gizi, pentingnya perbaikan gizi dan kesehatan remaja, calon pengantin (catin), bumil, dan ibu nifas, serta anak balita termasuk bagi anak PAUD. Perlu penguatan dan perluasan cakupan program gizi sensitif terkait Stunting (air, pangan, sanitasi, pendidikan, infrastruktur, akses pelayanan dan ekonomi). Dalam penelitian ini upaya pencegahan Stunting dilakukan dengan pendidikan gizi melalui penyuluhan di klinik Mariana Medan.

\section{METODE}

Jenis penelitian ini adalah Quasyexperiment. Penelitian ini bertujuan untuk menganalisa efektifitas penyuluhan kesehatan terhadap pengetahuan pencegahan Stunting pada ibu hamil.

Adapun yang menjadi hipotesis dalam penelitian ini adalah diduga bahwa adanya efektiiftas penyuluhan kesehatan terhadap pengetahuan pencegahan terhadap pengetahuan pencegahan Stunting pad ibu hamil.

Lokasi penelitian dilaksanakan di Klinik Mariana Medan. Penelitian ini dilakukan mulai bulan Mei 2020, setelah mendapatkan surat izin penelitian dari LPPM UNPRI.

Populasi dalam penelitian ini adalah ibu hamil yang ada di Klinik Mariana sebanyak 50 orang. Besar sampel dalam penelitian ini sebanyak 20 responden, yang diambil secara proportional stratified random sampling.

Setelah mendapat izin dari Klinik Mariana, kemudian peneliti mengumpulkan data dengan menggunakan cara pengisian kuesioner. Peneliti melakukan 2 kali pengukuran pengetahuan dimana sebelum dilakukan penyuluhan responden diberikan kuesioner dan sesudah itu melakukan penyuluhan kesehatan.

Analisis bivariat dilakukan untuk mengetahui efektifitas penyuluhan kesehatan terhadap pengetahuan 
pencegahan Stunting pada ibu hamil dengan menggunakan uji Wilcoxon.

Hasil uji Wilcoxon dengan derajat kemaknaan $(\alpha)$ 0,05. Kemudian hasil penelitian dilanjutkan dalam bentuk tabel dan dibahas dengan menggunakan teori dan kepustakaan yang ada.

\section{HASIL DAN PEMBAHASAN}

\section{Hasil Penelitian}

Berdasarkan hasil penelitian diketahui bahwa ada efektifitas penyuluhan kesehatan terhadap pengetahuan pencegahan Stunting pada ibu hamil.

Penyuluhan

kesehatan

diselenggarakan guna meningkatkan pengetahuan, kesadaran, kemauan, dan kemampuan ibu untuk tetap memberikan gizi yang baik selama kehamilan. Pengetahuan tentang pemberian makanan sejak hamil untuk mencegah terjadinya Stunting. Penelitian yang berfokus pada intensi, motivasi, dan pengetahuan tidak cukup untuk membantu ibu mengatassi hambatan selama kehamilan. Selain mendapatkan penyuluhan, ibu mengatasi hambatan selama hamil. Selain mendapatkan penyuluhan ibu memerlukan dukungan, edukasi dan informasi yang konsisten, realistis, dan evidance-based agar berhasil memperbaiki gizi selama kehamilan.

Tabel 1. Distribusi Frekuensi Sebelum dan Sesudah Penyuluhan Kesehatan Terhadap Pengetahuan Pencegahan Stunting pada Ibu Hamil

\begin{tabular}{lrrlrr}
\hline \multicolumn{1}{c}{$\begin{array}{c}\text { Penyuluhan } \\
\text { Sebelum }\end{array}$} & \multicolumn{1}{c}{$\boldsymbol{f}$} & \multicolumn{1}{c}{$\boldsymbol{\%}$} & \multicolumn{1}{c}{$\begin{array}{c}\text { Penyuluhan } \\
\text { sesudah }\end{array}$} & \multicolumn{1}{c}{$\boldsymbol{f}$} & \multicolumn{1}{c}{$\%$} \\
\hline Baik & 12 & 60 & Baik & 18 & 90 \\
Cukup & 6 & 30 & Cukup & 2 & 10 \\
Kurang & 2 & 10 & Kurang & & \\
Total & 20 & 100 & Total & 20 & 100 \\
\hline
\end{tabular}

Tabel 2. Efektifitas Penyuluhan Kesehatan Terhadap Pengetahuan Pencegahan Stunting pada Ibu Hamil

\begin{tabular}{|c|c|c|c|c|c|c|c|c|c|}
\hline \multirow{3}{*}{$\begin{array}{c}\text { Penyuluhan } \\
\text { Kesehatan }\end{array}$} & \multicolumn{6}{|c|}{ Pengetahuan } & \multirow{3}{*}{$\mathbf{N}$} & \multirow{3}{*}{$\mathbf{Z}$} & \multirow{3}{*}{$p$-value } \\
\hline & \multicolumn{2}{|c|}{ Baik } & \multicolumn{2}{|c|}{ Cukup } & \multicolumn{2}{|c|}{ Kurang } & & & \\
\hline & $f$ & $\%$ & $f$ & $\%$ & $f$ & $\%$ & & & \\
\hline Pre Test & 12 & 60 & 6 & 30 & 2 & 10 & 20 & -2828 & 0002 \\
\hline Post Test & 18 & 90 & 2 & 10 & 0 & 0 & 20 & $-2,0<0$ & 0,002 \\
\hline
\end{tabular}

Berdasarkan tabel diatas dapat penyuluhan kesehatan terhadap diketahui bahwa hasil uji wilcoxon pengetahuan pencegahan Stunting pada terdapat nilai $\mathrm{Z}=-2,828$ dengan $p$-value ibu hamil.

sebesar $0,002<0,05$ sehingga keputusan

hipotesis Ho ditolak ha diterima, Pembahasan

disimpulkan bahwa ada efektifitas 
Efektifitas Penyuluhan Kesehatan terhadap Pengetahuan Pencegahan Stunting pada Ibu Hamil

Masalah Stunting dipengaruhi oleh rendahnya akses terhadap makanan dari segi jumlah dan kualitas gizi, serta seringkali tidak beragam. Stunting dipengaruhi oleh pola asuh yang kurang baik terutama pada aspek perilaku, terutama pada praktek pemberian makan bagi bayi dan Balita. Stunting dapat dipengaruhi dengan rendahnya akses terhadap pelayanan kesehatan, termasuk di dalamnya adalah akses sanitasi dan air bersih. Pola asuh dan status gizi sangat dipengaruhi oleh pemahaman orang tua (seorang ibu) maka, dalam mengatur kesehatan dan gizi di keluarganya edukasi diperlukan agar dapat mengubah perilaku yang bisa mengarahkan pada peningkatan kesehatan gizi atau ibu dan anaknya (Kemenkes RI, 2018). Status gizi ibu hamil sangat mempengaruhi keadaan kesehatan dan perkembangan janin ((Ni`mah Khoirun \& Nadhiroh, 2015). Gangguan pertumbuhan dalam kandungan dapat menyebabkan berat lahir rendah (WHO, 2014).

Status sosial ekonomi keluarga seperti pendapatan keluarga, pendidikan orang tua, pengetahuan ibu tentang gizi, dan jumlah anggota keluarga secara tidak langsung dapat berhubungan dengan kejadian Stunting (Ni`mah Khoirun \& Nadhiroh, 2015). Stunting adalah masalah kurang gizi kronis yang disebabkan oleh kurangnya asupan gizi dalam waktu yang cukup lama, sehingga mengakibatkan gangguan pertumbuhan pada anak yakni tinggi badan anak lebih rendah atau pendek (kerdil) dari standar usianya (Kementerian Kesehatan RI, 2018).

Keluarga dengan pendapatan yang tinggi lebih mudah memperoleh akses pendidikan dan kesehatan sehingga status gizi anak dapat lebih baik. Faktor ibu menjadi faktor resiko untuk Stunting antara lain ibu dengan anemia dan kurang gizi saat hamil dapat memiliki resiko lebih tinggi dibanding dengan ibu yang tidak mengalami anemia atau kekurangan gizi saat hamil, serta pendidikan ibu yang rendah memiliki resiko lebih tinggi dibandingkan ibu dengan pendidikan tinggi.

Penyuluhan kesehatan dianggap suatu upaya untuk menjembatani adanya kesenjangan antara informasi kesehatan dan juga prakteknya. Apabila informasi kesehatan yang dimiliki telah benar maka akan memotivasi ibu balita untuk menerapkan informasi tersebut salah satunya adalah informasi mengenai gizi balita. Hal tersebut dapat mencegah balita mengalami kekurangan gizi di masa emas yaitu masa pertumbuhan dan perkembangannya.

Semakin tinggi tingkat pengetahuan ibu balita maka akan semakin mudah ibu 
menerapkan informasi kesehatan tersebut. Dengan informasi yang benar mengenai kesehatan gizi, maka ibu balita akan menyediakan makanan bagi balita dengan tepat baik dari segi kuantitas maupun kualitas. Tersedianya makanan yang seimbang bagi balita maka angka kecukupan gizi balita dapat terpenuhi dengan baik

\section{KESIMPULAN DAN SARAN}

\section{Kesimpulan}

Hasil penelitian akhir dengan menggunakan uji wilcoxon diperoleh bahwa nilai $\mathrm{Z}=-2,828$ dan nilai $p$-value $=0,002<0,05$ maka, ada ada efektivitas penyuluhan kesehatan terhadap pengetahuan pencegahan Stunting pada ibu hamil di klinik Mariana Medan.

\section{Saran}

Bagi ibu hamil agar rajin mengkonsumsi makanan yang bergizi agar pertumbuhan dan perkembangan janin normal untuk mencegah terjadinya Stunting. Rajin membaca media cetak atau media elektronik tentang pencegahan Stunting. Keluarga terutama suami diharapkan dapat memberikan dukungan kepada ibu hamil untuk memenuhi nutrisinya.

Bagi petugas kesehatan agar lebih memahami tentang pencegahan Stunting dan memberikan pendidikan kesehatan kepada ibu hamil dengan memberikan informasi secara tertulis maupun diskusi serta metode dan media yang dapat tepat untuk dapat meningkatkan pengetahuan ibu hamil yang ada di klinik Mariana.

\section{UCAPAN TERIMA KASIH}

Terima kasih kepada Kementerian Riset, Teknologi, dan Pendidikan Tinggi yang telah memberikan kesempatan untuk mendapatkan hibah Penelitian Dosen Pemula (PDP) berdasarkan Surat B/196/M/KU.00.01/2020, dengan Kontrak Penelitiain Dasar dan Penelitian Terapan Tahun Anggaran 2019 antara LPPM Universitas Prima Indonesia dengan Dosen Peneliti Nomor 282/LL1/PG/2020.

\section{DAFTAR PUSTAKA}

Bishwakarma, R. (2011). Spatial inequality in child nutrition in Nepal: Implications of regional context and individual/household composition. ProQuest Dissertations and Theses.

FAO. (2019). Global report on food crises. Food Security Information Network.

Kemenkes RI. (2018). Situasi Balita Pendek (Stunting) di Indonesia. Pusat Data dan Informasi Kesehatan, Kementerian Kesehatan RI. In Buletin Jendela Data dan Informasi Kesehatan.

Kementerian Kesehatan RI. (2018a). Laporan Riskesdas 2018. Laporan Nasional RIskesdas 2018.

Kementrian Kesehatan RI. (2018b). Situasi Balita Pendek (Stunting) di Indonesia. Kementerian Kesehatan $R I$.

Ni`mah Khoirun, \& Nadhiroh, S. R. (2015). Faktor Yang Berhubungan Dengan Kejadian Stunting Pada Balita. Media Gizi Indonesia. 
TNP2K. (2017). 100 Kabupaten/Kota Prioritas untuk Intervensi Anak Kerdil (Stunting): Tim Nasional Percepatan Penanggulangan Kemiskinan. Jakarta.

Unicef. (2018). Levels and Trends in Child Malnutrition, UNICEF / WHO / World Bank Group Joint Child Malnutrition Estimates. Midwifery.

UNICEF. (2012). Ringkasan Kajian Kesehatan Ibu \& Anak. UNICEF Indonesia.

World Health Organization (WHO). (2014a). Global Nutrition Targets 2025. Canadian Pharmaceutical Journal.

World Health Organization (WHO). (2014b). Stunting policy brief. Global Nutrition Targets. 